\title{
Tele-Pharmacistsin Pandemic Situations of Bangladesh
}

\author{
Abdul Kader Mohiuddin* \\ Nasirullah Memorial Trust, Tejgaon, Bangladesh
}

*Corresponding author: Abdul Kader Mohiuddin, Nasirullah Memorial Trust, Tejgaon, Bangladesh.

Received Date: April 13, 2020

Published Date: May 19, 2020

\section{Mini Review}

Bangladesh's health care services are becoming unusually concentrated in a small fraction of costly critical health-demanding patients. A large part of these complex-patients suffer from multiple chronic diseases and are spending a lot of money. Currently, coronavirus COVID-19 has affected 203 countries around the world,killed more than 42,000 and infected more than 860,000 [1]. Home-care is especially important in these situations because hospitals are not seemingly safe during pandemicoutbreaks. Also, the chance to get out of the home during the lockdown period is limited. Telemedicine and telehealth technologies are especially effective during epidemic outbreaks, when health authorities recommend implementing social distance systems. Telephonebased measures improve efficiency by linking appropriate information and feedback. In addition to increasing access to healthcare, telemedicine is a fruitful and proactive way to provide a variety of benefits to patients seeking healthcare; diagnose and monitor critical and chronic health conditions; improve healthcare quality and reduce costs.

The rise of pharmacists in epidemic situations has become increasingly popular in developed countries such as the United States, Australia, Canada and the United Kingdom. According to information from recent published articles in several ongoing journals, books, newsletters, magazines, etc., the duties, authority and responsibilities of pharmacists are completely different from doctors and nurses, although there are some similarities. Along with doctors, pharmacists can serve as frontline healthcare workers during epidemics. The profession is developed and highly praised in both developed and underdeveloped countries. Millions of professional pharmacists worldwide work in various organizations, and according to data from the International Pharmaceutical Federation (FIP), nearly $75 \%$ of them work in patient care [2]. Even in the United States, the continued lacking of primary health providers and medical specialists has made it possible for pharmacists to care for ambulatory patients with chronic diseases in a variety of treatment services [3].

However, pharmacy is taught in about 100 public and private universities in Bangladesh and about 8000 pharmacy students graduate every year [4]. At present, Hospital Pharmacy has created enormous job opportunities, where graduate pharmacists play a vital role in patient rearing, rehabilitation and wellness. A professional pharmacist or a pharmacy apprentice at a clinic, hospital and community care can determine what to do in a given disease situation, if guided properly by another medical personnel. The country has a huge opportunity to recruit these pharmacists at Telehealth Care. In each call, a pharmacist can provide both appropriate and quality information from the most recent medical systems. Studies show that the lack of proper medication management leads to higher healthcare costs, longer hospital stays, morbidity and mortality. Further, it was reported that one in every five hospitalizations was related to post-discharge complications and about seventy percent were related to proper use of the drug. In 2017, the World Health Organization committed to minimizing serious, avoidable drug-related harm over the next 5 years. Pharmacists' interventions to prevent drug-related problems at three community hospitals in California saved approximately 0.8 million USD in a year [5].The estimated annual cost of medication error-based illnesses and deaths worldwide was USD 500 billion due to non-compliance with the clinical intervention and quantities 
in 2016. Also, the authors estimate that more than 275,000 people die every year for the same reasons [6]. A pharmacist can use simple and non-medical terminology to set the goal for patients to understand the information as well as to fulfill the prescription by proper request. With chronic conditions such as cardiovascular and respiratory diseases, there is ample evidence of the effectiveness of the tele-pharmacist for remote monitoring, communication and consultation [7]. In addition, psychotherapy can also be operated through tele-health as part of behavioral health [8]. At the end, it can be said that pharmacists can play a role in both medical aids and regulation. Similarly, in tele-healthcare, the professional pharmacist can play an essential role that has not been recognized yet due to lack of proper initiatives. We hope that policy makers of Bangladesh are aware of its potential and contribute to the wider promotion of tele-pharmacy services in the interest of the citizenry.

\section{Acknowledgement}

None.

\section{Conflicts of Interest}

None.

\section{References}

1. Preeti Soni (2020) These 9 countries have managed to stay away from Covid-19-one of them even banned the word 'coronavirus'. Business Insider India.

2. Bates I, John C, Bruno A, Fu P, Aliabadi S (2016) An analysis of the global pharmacy workforce capacity. Hum Resour Health 14(1): 61.

3. Goode JV, Owen J, Page A, Gatewood S (2019) Community-Based Pharmacy Practice Innovation and the Role of the Community-Based Pharmacist Practitioner in the United States. Pharmacy (Basel) 7(3): 106.

4. Mazid MA, Rashid MA (2011) Pharmacy Education and Career Opportunities for Pharmacists in Bangladesh. Bangladesh Pharmaceutical Journal 14(1): 1-9.

5. Schneider PJ (2013) Evaluating the impact of telepharmacy. Am J Health Syst Pharm 70(23): 2130-2105.

6. Watanabe JH, McInnis T, Hirsch JD (2018) Cost of Prescription DrugRelated Morbidity and Mortality. Ann Pharmacother 52(9): 829-837.

7. Littauer SL, Dixon DL, Mishra VK, Sisson EM, Salgado TM. Pharmacists providing care in the outpatient setting through telemedicine models: a narrative review. Pharm Pract (Granada). 2017;15(4):1134. doi:10.18549/PharmPract.2017.04.1134

8. Langarizadeh M, Tabatabaei MS, Tavakol K, Naghipour M, Rostami A, et al. (2017) Telemental Health Care, an Effective Alternative to Conventional Mental Care: a Systematic Review. Acta Inform Med 25(4): 240-246. 